\section{High frequency microseismic noise as possible earthquake precursor}

\author{
Ivica Sović, ${ }^{1}$ Kristina Šariri, ${ }^{2}$ \\ Mladen Živčić ${ }^{3}$
}

'Department of Geophysics, Faculty

of Science, University of Zagreb, Zagreb,

Croatia; ${ }^{2}$ P. Preradovića 27, Valpovo,

Croatia; ${ }^{3}$ Seismology Office,

Environmental Agency of the Republic

of Slovenia, Ljubljana, Slovenia

\section{Abstract}

Before an earthquake occurs, microseismic noise in high frequency (HF) range, i.e. 2-25 $\mathrm{Hz}$, is being generated during preparation process. These signals change the microseismic noise and, consequently, the spectrum of microseismic noise. Time variation of spectra recorded at the same seismological station could imply the change of the state of noise source. We propose the image moment analysis approach to objectively compare microseismic noise spectra. The result could be used for earthquake precursor identification. Expected spectra change is in HF range, so the analysis has been limited to the shallow tectonic earthquakes with epicenters close, up to $15 \mathrm{~km}$, the seismological stations. The method has been tested post festum using four earthquakes in Dinarides which satisfied condition for epicentral distance. The spectra were calculated for noise recorded in time intervals of 10 days before and 6 to 10 days after the earthquakes. Affine moment invariants were calculated for noise spectra which were treated as the input objects. Spectra of the first five days in the series were referent spectra. The classification parameters were Euclidean distances between referent spectra and the spectra for all days in the series, including referent ones. The results have shown that the spectra of the microseismic noise become noticeably different than the other spectra in time intervals one or two days before an earthquake.

\section{Introduction}

It has been found that a large number of different geophysical phenomena, i.e. precursors, occur or vary before the earthquakes. One of the precursors that could be useful for earthquake prediction is the variation of microseismic noise. Every variation of noise changes its spectrum, so it is enough to monitor changes of spectrum. Spectrum of microseismic noise is one dimensional (1D) object. Two or more spectra can be compared by the correlation. Unfortunately, correlation does not give satisfactory results, so we treated spectra as 2D objects and compare their images by image moments method. This method was not previously used for extracting information from high frequency (HF) microseismic noise (above $2 \mathrm{~Hz}$ ) generated in the vicinity of the seismological station. Seismological stations record noise all the time, so implementation of prediction method based on noise does not require additional hardware.

There already have been some efforts to apply microseismic noise spectra in order to identify earthquake precursors. We will give short overview of a few of them. Lyubushin ${ }^{1}$ used low frequency part of microseismic noise to identify change in fractal dimension of the faults. By this method he predicted 2011 M9.0 Tohoku earthquake. ${ }^{2}$ Similar drop of fractal dimension had been observed by Lu, Mai and $\mathrm{Xie}^{3}$ and connected to precursor of failure in disordered media. Levy ${ }^{4}$ reported about modulation of short period microseismic noise generated by sea waves prior an earthquake in Bulgaria on Dec 7, 1986, M5.7. He suggested that the modulation can be caused by the strains around local lithospheric plates. Sobolev and Lyubushin ${ }^{5}$ identified microseismic pulses in the seismic noise before Kronotskii (Kamchatka) M7.7 earthquake on Dec 5, 1997 and Neftegorsk (Sakhalin) M7.0 earthquake on May 27, 1995 and interpreted them as the earthquake precursor. The pulses are, usually, asymmetrical pulsed vibrations several minutes long and separated by the intervals of a several tens of minutes. The authors concluded that the origin of the phenomenon could be inelastic motion along the fault in the hypocenter of forthcoming earthquake, self-organization properties of the seismic process, and synchronization of vibrations in the inner and outer shells of the Earth.

The major premise of this work is applicability of the image moments analysis method for detecting changes in the spectra of microseismic noise. Main hypothesis is that preparation process of shallow tectonic earthquakes affects HF part of microseismic noise and that this influence can be detected. If change of microseismic noise really contains information about process in earthquake source, then it could be useful short-term short-range precursor. We presume that precursor capability of $\mathrm{HF}$ noise can be extracted by the image moments method.

The change of HF microseismic noise spectra before occurrence of an earthquake could be result of the acoustic emission ${ }^{6,7}$ during preparation process in the hypocenter area. Champin and Evans ${ }^{8}$ suggested that the earthquakes are preceded by differential opening and growth of existing cracks. This process
Correspondence: Ivica Sović, Seismological Survey, Faculty of Science, Horvatovac 95, 10000 Zagreb, Croatia. Tel. +385.14605917.

E-mail: sovic@irb.hr

Key words: microseismic noise, earthquake precursor, affine moment invariants.

Contributions: the authors contributed equally.

Conflict of interests: the authors declare no potential conflict of interests.

Funding: the work was supported by MZOS project 119-1193086-1315.

Conference presentation: part of this paper was presented at the ESC 33rd General Assembly, 19 24 August 2012, Moscow, Russia.

Received for publication: 27 May 2013.

Revision received: Not required.

Accepted for publication: 10 June 2013.

This work is licensed under a Creative Commons Attribution NonCommercial 3.0 License (CC BYNC 3.0).

(C) Copyright et al., 2013

Licensee PAGEPress, Italy

Research in Geophysics 2013; 3:e2

doi:10.4081/rg.2013.e2

affects a large part of volume of the preparation area and could be responsible for $\mathrm{HF}$ noise. Acoustic emission could be produced by non-uniformity of crack growth. ${ }^{9}$ It could, also, be caused by growing number of picoforeshocks (according to picoearthquake ${ }^{10,11}$ ) which follow inverse Omori's law ${ }^{12}$ but are too weak to be recorded by seismographs ${ }^{13}$ and located as individual events, and, consequently, are not able to satisfy Gutenberg-Richter magnitude-number distribution. ${ }^{14}$

All mentioned processes are, basically, the same from our point of view as we treat additional HF source associated with preparation process. We have compared ambient noise spectra calculated from 30 min long samples. Samples have been recorded every day at the same time. The time intervals were between 16 and 21 days long. Short time intervals of maximum 21 days were chosen to avoid seasonal variations of the noise. Investigated earthquakes occurred 10 days after the beginning of time intervals. Spectra have been compared for additional 6 to 10 days after the earthquakes too. We also wanted to avoid influence of foreshocks on the shape of the analyzed spectra, so we considered only small and moderate earthquakes. They are, usually, not preceded by foreshock. Since picoseismicity, ${ }^{15,16}$ which is part of earthquake preparation process, changes the spectra in $\mathrm{HF}$ range and 
the rocks strongly attenuate high frequencies, ${ }^{17}$ our investigation is limited to the earthquakes with epicenters closer than $15 \mathrm{~km}$ to the seismological stations. Distance of $15 \mathrm{~km}$ has been estimated from empiric data. It agrees very well with maximum contribution distance for seismic noise sources ${ }^{14} r=Q v / 2 \pi f$ for frequency $\mathrm{f}=7 \mathrm{~Hz}$, quality factor $\mathrm{Q}=200$ and velocity $\mathrm{v}=3.5 \mathrm{~km} / \mathrm{s}$ valid in Dinarides. ${ }^{18}$ Limit of $15 \mathrm{~km}$ possess additional advantage too, because high frequencies carry information about preparation process only in the vicinity of seismological station and improve spatial resolution of the predicted earthquake.

Low frequency (LF) part of spectra has been cut out because it scales image of the spectra to the high values of the LF part which mainly depend on weather conditions, tides and sea waves. LF part of spectra depends on seismological sources too, mainly on the preparation processes of strong and distant earthquakes. ${ }^{1}$ Influence of distant sources on the shape of spectra is treated as a disturbance in prediction of local earthquakes. It is known that hypocentral area before an earthquake emits or modifies broad scale of elastic waves and impulses which could be used as precursors. Chosen frequency range determinates spatial dimension of area which will contain future focus (higher frequency - smaller area). Because the method described in this paper works with HF part of spectra, for successful application of method high density network with spatial distribution of seismographs at least every $20 \mathrm{~km}$ is needed. Dimension of area in which HF emission occurred and position of possible fault activated could be estimated from the number of the stations affected by the precursor. Of course, the magnitude of single predicted earthquake could not be assessed from the dimension of area affected by precursors, ${ }^{19}$ but possible cumulative energy of foreshocks, main shock and aftershocks could be.

\section{Materials and Methods}

\section{Preparation of the input images}

Maximum distance from the earthquake epicenter to seismograph was empirically set to 15 kilometers. These criteria satisfied four recently catalogued earthquakes in the Dinaric karst region (Table 1). Data had been recorded at the three seismological stations: Banja Luka (BLY) (Bosnia and Herzegovina), Čačvina (CACV) (Croatia) and Kijevo (KIJV) (Croatia) (Table 2). Seismological stations CACV and KIJV are part of Croatian seismological network. The data for BLY were obtained from ORFEUS. ${ }^{20}$ Geographic location of all stations is shown in Figure 1.

Since all three seismological stations are located more than $20 \mathrm{~km}$ (Figure 1) from the sea shore (BLY is $150 \mathrm{~km}$, KIJV $50 \mathrm{~km}$, and CACV about $25 \mathrm{~km}$ from the Adriatic sea), the main contribution to HF noise origins from human and atmospheric sources. Noise caused by earthquake preparation is an exception. Noise produced by human sources (traffic, machinery etc.) mostly propagates in form of HF surface waves $(1-10 \mathrm{~Hz})$ which attenuate within a few $\mathrm{km} .{ }^{21}$ Seismological stations CACV and KIJV are located more than $2 \mathrm{~km}$ from the roads and rivers, so the influence of the traffic is reduced and can be ignored.
Unfortunately, station BLY is about $200 \mathrm{~m}$ from the river and $300 \mathrm{~m}$ from the road and it is reasonable to suppose that considerable part of the signal is contaminated by, mainly, traffic noise. Diurnal variations from human sources highly depend on the time of the day.2 ${ }^{22}$ To a great degree, these disturbances were removed from analysis by taking samples at the same time each day. Significant atmospheric disturbances, mostly strong winds, rain and pressure changes, were identified by checking local meteorological conditions for

Table 1. Parameters of earthquakes considered in analysis: $h$ is hypocentral depth, $M_{L}$ local magnitude, NS nearest seismological station, $\Delta$ epicentral distance from NS and NOS number of spectra considered.

\begin{tabular}{lcccccccc}
\hline Date & Time (UIC) & \multicolumn{2}{c}{ Epicenters } & h $(\mathrm{km})$ & ML & NS & $\Delta(\mathrm{km})$ & NOS \\
Apr 28 2011 & $23: 30: 42.9$ & $44.74 \mathrm{~N}$ & $17.32 \mathrm{E}$ & 13.4 & 4.7 & BLY & 10 & 21 \\
Jun 17 2011 & $05: 31: 04.7$ & $43.80 \mathrm{~N}$ & $16.52 \mathrm{E}$ & 6.3 & 4.0 & KIJV & 13 & 17 \\
\hline Dec 4 2011 & $17: 05: 16.2$ & $43.63 \mathrm{~N}$ & $16.78 \mathrm{E}$ & 15.8 & 1.0 & CACV & 5 & 16 \\
Dec 10 2011 & $17: 17: 25.7$ & $43.74 \mathrm{~N}$ & $16.85 \mathrm{E}$ & 3.5 & 3.7 & CACV & 15 & 16 \\
\hline
\end{tabular}

BLY, Banja Luka; KIJV, Kijevo; CACV, Čačvina.

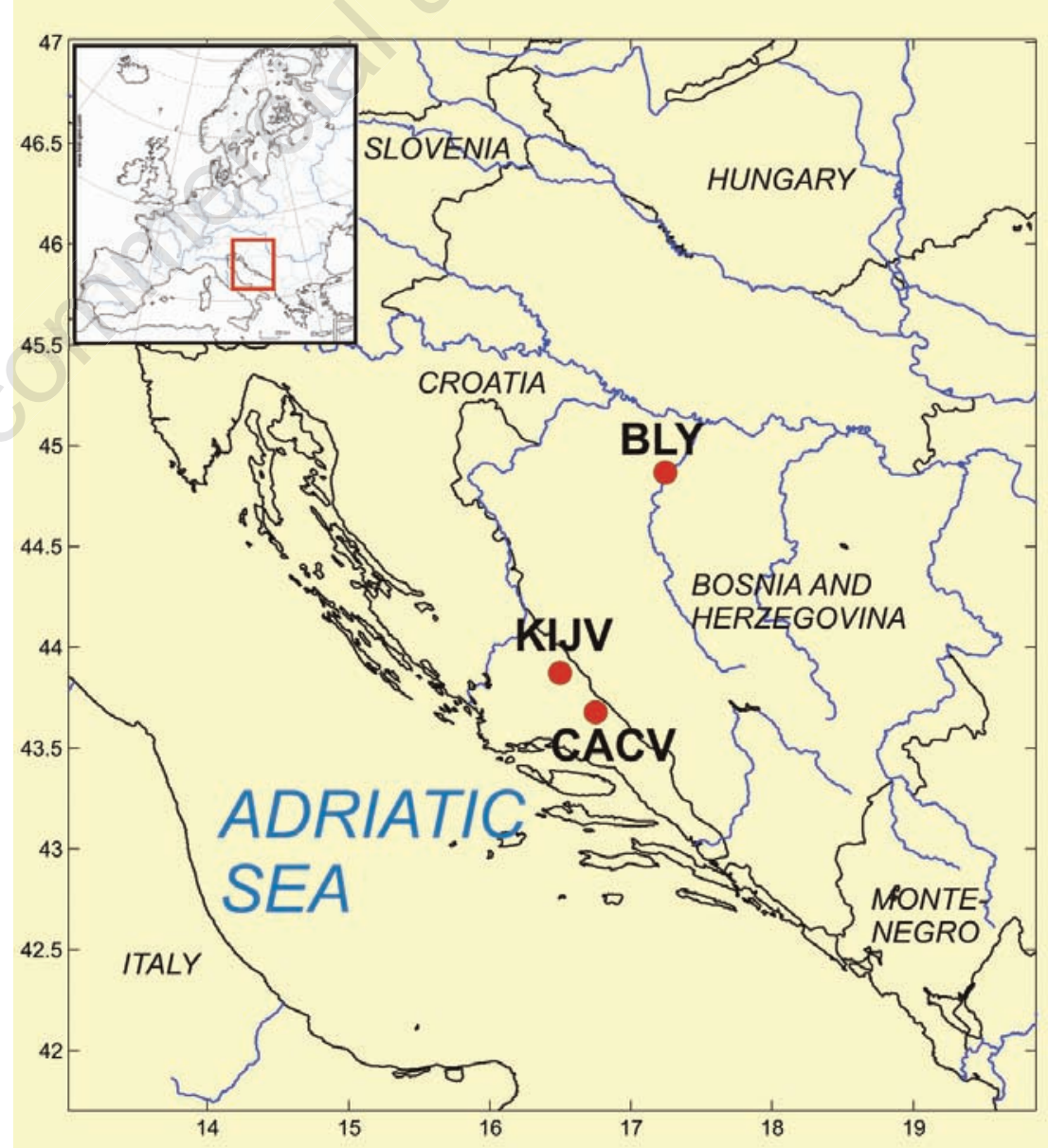

Figure 1. Positions of seismological stations Banja Luka (BLY), Čačvina (CACV) and Kijevo (KIJV). 
days considered. There was one front passage over BLY station and its influence is clearly seen on Figure 2.

All seismometers were three component broadband (Guralp and Streckeisen) devices with sampling rate of $50 \mathrm{~Hz}$ (KIJV and CACV) and $20 \mathrm{~Hz}$ (BLY) (Table 2). Only vertical components of the recorded signals were considered in order to exclude azimuthal effects. The influence of atmospheric disturbances as the major source of low frequency noise was diminished by cutting of LF end of the spectra. We also tried to avoid earthquakes with foreshocks identifiable on seismogram since we assumed that they contribute HF disturbances to the microseismic noise signal.

\section{Feature extraction}

Spectra of microseismic noise were obtained in the following way. For each day in time series which include 10 days preceding and 6 to 10 days following an earthquake: i) records 30 min long were cut out from digital seismograms, each day at the same time. These time-domain records contain more than 36,000 samples each and were used as inputs for spectra calculation. To ensure data quality, all inputs were manually checked to maximally reduce the most obvious disturbances; ii) each spectrum has been calculated from 16,384 samples by fast Fourier transform algorithm. Spectrum amplitude has been calculated as $A(f)=\left(\operatorname{Re}(f)^{2}+\operatorname{Im}(f)^{2}\right)^{1 / 2}$, where $\operatorname{Re}(f)$ and $\operatorname{Im}(f)$ are real and imaginary parts of spectrum; iii) LF part of the spectrum, i.e. the first $\mathrm{Hz}$ (655 samples for KIJV and CACV, 1638 samples in the case of station BLY) was left out in order to exclude the influence of atmospheric disturbance and distant sources. In this way, greater weight was given to the lobe of the spectrum (Figure 3 ). With this procedure 2D graphs of the spectra amplitudes were obtained and saved in the form of $595 \times 595$ binary images (Figure 4). These were input objects for the image moments analysis. In this way, the set of 21 images was associated to each earthquake occurrence.

\section{Affine invariants}

Affine deformations are linear transformations of the input image and include translation, rotation, scale change, bending, stretching and their linear combinations. In cases when input objects are deformed by such operations, comparison by using affine invariants proved useful. ${ }^{23,24}$ They were successfully applied in recognition of objects, ${ }^{25}$ as well as in analysis of satellite images. ${ }^{26}$ They are obtained from geometrical moments defined by:

$$
m_{p q}=\int_{-\infty}^{\infty} x^{p} y^{q} f(x, y) d x d y
$$

Centralized version with translational invariance in object domain $O$ is given with:

$$
m_{p q}^{\prime}=\iint_{\delta}\left(x-x_{c}\right)^{p}\left(y-y_{c}\right)^{q} f(x, y) d x d y
$$

where

$$
\left(x_{c}, y_{c}\right)=\left(\frac{m_{10}}{m_{00}}, \frac{m_{01}}{m_{00}}\right)
$$

are coordinates of the image centroid.

Now it is possible to calculate the set of the first six affine invariants:

$$
\begin{aligned}
& I_{1}=\frac{m_{20}^{\prime} m_{02}^{\prime}-m_{11}^{\prime 2}}{m_{\infty}^{\prime}{ }^{4}} \\
& I_{2}=\frac{m_{30}^{\prime}{ }^{2} m_{03}^{\prime}{ }^{2}-6 m_{30}^{\prime} m_{21}^{\prime} m_{12}^{\prime} m_{03}^{\prime}+}{\frac{4 m_{30}^{\prime} m_{12}^{\prime}+4 m_{21}^{\prime} m_{30}^{3}-3 m_{21}^{\prime} m_{12}^{\prime}{ }^{2}{ }^{2}}{m_{00}^{\prime}{ }^{10}}} \\
& I_{3}=\frac{m_{20}^{\prime}\left(m_{21}^{\prime} m_{03}^{\prime}-m_{12}^{\prime}{ }^{2}\right)-m_{11}^{\prime}\left(m_{30}^{\prime} m_{03}^{\prime}-m_{21}^{\prime} m_{12}^{\prime}\right)+}{m_{03}\left(m_{30}{ }_{12}-m_{2}^{\prime}\right)} \\
& \underline{m_{02}^{\prime}\left(m_{30}^{\prime} m_{12}^{\prime}-m_{21}^{\prime}{ }^{2}\right)} \\
& m_{\infty}^{\prime}{ }^{\top} \\
& I_{4}=m_{20}^{\prime 2}\left(6 m_{11}^{\prime} m_{12}^{\prime} m_{03}^{\prime}-3 m_{02}^{\prime} m_{12}^{\prime}-m_{20}^{\prime} m_{03}^{\prime 2}\right)- \\
& 6 m_{20}^{\prime} m_{11}^{\prime 2}\left(m_{12}^{\prime 2}+m_{21}^{\prime} m_{03}^{\prime}\right) \\
& +3 m_{20}^{\prime} m_{02}^{\prime} m_{21}^{\prime}\left(4 m_{11}^{\prime} m_{12}^{\prime}-m_{02}^{\prime} m_{21}^{\prime}\right) \\
& +2 m_{11}^{\prime 2}\left(m_{11}^{\prime} m_{30}^{\prime} m_{03}^{\prime}+3 m_{11}^{\prime} m_{21}^{\prime} m_{12}^{\prime}\right. \\
& \left.-3 m_{02}^{\prime} m_{30}^{\prime} m_{12}^{\prime}-3 m_{02}^{\prime} m_{21}^{\prime 2}\right)+m_{02}^{\prime} m_{30}^{\prime} \\
& \left(6 m_{11}^{\prime} m_{02}^{\prime} m_{21}^{\prime}-m_{02}^{\prime 2} m_{30}^{\prime}\right) / m_{00}^{\prime 11} \\
& I_{5}=\left(m_{40}^{\prime} m_{04}^{\prime}-4 m_{31}^{\prime} m_{13}^{\prime}+3 m_{22}^{\prime}\right) / m_{00}^{\prime 6} \\
& I_{6}=\left(m_{40}^{\prime} m_{04}^{\prime} m_{22}^{\prime}+2 m_{31}^{\prime} m_{22}^{\prime} m_{13}^{\prime}-m_{40}^{\prime}\right. \\
& \left.m_{13}^{\prime 2}-m_{04}^{\prime} m_{31}^{\prime 2}-3 m_{22}^{\prime 3}\right) / m_{00}^{\prime 9}
\end{aligned}
$$

Procedure applied in obtaining measure of similarity between two images, $i$ and $j$ was as follows: i) calculating the set of geometric moments and affine moment invariants; ii) comparison of each invariant in the set to the corresponding invariant of the other image according to the formula for Euclidean distance $D_{i j}$ between images $i$ and $j$ :

$$
D_{i j}=\sum_{k=1}^{6}\left|\left(I_{k}\right)_{i}-\left(I_{k}\right)_{j}\right|
$$

where $k$ is index of affine invariant; all the $D_{i j}$ were compared and plotted as a graphs.

\section{Comparing process}

Each spectrum is represented with a point in 6D space of affine invariants. Euclidean distance between two points is now the unit of dissimilarity of their spectra. Because of the random nature of microseismic noise, spectra of the days in the time series should be randomly similar to the first five (referent) spectra. Activation of additional source of HF waves changes the spectrum of microseismic noise and it becomes noticeably different comparing to the referent spectra.

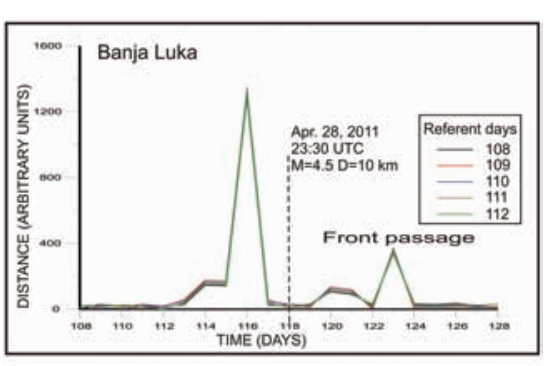

Figure 2. Euclidean distance in 6D space of affine invariants at Banja Luka station from April $18\left(108^{\text {th }}\right.$ day of the year) to May $8\left(128^{\text {th }}\right.$ day of the year $), 2011$. Colors indicate different referent day. Dashed vertical line denotes day of the earthquake. Sampling time: 22:00 UTC.

Table 2. Coordinates of seismological stations Banja Luka, Kijevo and ČaČvina, type of seismograph and sampling frequency.

\begin{tabular}{lcccc} 
Station & \multicolumn{2}{c}{ Coordinates } & Seismograph & Sampling frequency (Hz) \\
BLY & $44.75 \mathrm{~N}$ & $17.18 \mathrm{E}$ & Streckeisen STS - 2 & 20 \\
KIJV & $44.01 \mathrm{~N}$ & $16.40 \mathrm{E}$ & Guralp CMG - 3T & 50 \\
\hline CACV & $43.61 \mathrm{~N}$ & $16.79 \mathrm{E}$ & Guralp CMG - 3T & 50 \\
\hline BLY Banja Luka: KIJV Kijevo; CACV Čačina & & &
\end{tabular}

BLY, Banja Luka; KIJV, Kijevo; CACV, Čačvina.. 


\section{Results}

The results of the comparing process have been shown in Figures 2, 5 and 6. On the horizontal axes are ordinal numbers of the days in the year, and on the vertical ones are Euclidean distances between spectra of referent and other days in the time series. Dissimilarity measure is a Euclidean distance between the points.

\section{Banja Luka}

BLY seismological station is located in the wood on the hill, $200 \mathrm{~m}$ southward from the river and the regional road. Microseismic noise at BLY station is extremely sensitive to weather conditions, particularly wind, because of the trees which surround the station. Figure 2 shows five lines in different colors of Euclidean distances between BLY station spectra and five referent spectra. In the case of random nature of microseismic noise source distances on different graphs for the same day should be randomly distributed and relatively small. Graphs presented in the Figure 2 show strong increase of Euclidean distance (i.e. dissimilarity) two days before the earthquake. The peaks in days after the earthquake belong to the atmospheric front passage. Average distance for the first four days in the time series was less than 50 . Four days before the earthquake distance arise more than three times, up to 166 . Two days before the earthquake distance jumped up to 1321 and the day after dropped to the value of 56. On the day of the earthquake, Apr 28, spectrum was very similar to spectra of referent days with distance smaller than 40 .

\section{Kijevo}

KIJV station is located on the southwestern side of Dinara Mountain in small village, five kilometers from Kijevo and regional road. There are no high trees around the station so the noise is not very sensitive to wind. Disturbance from human activity is possible but not probable because of the small number of village inhabitants. Distance between spectra (Figure 5) increased from 13 in first seven days to more than 50 the day before the earthquake.

\section{Ğvčina}

Seismological station CACV is situated in village Čačvina on Kamešnica Mountain, more than $2 \mathrm{~km}$ from the main road. As the KIJV station, CACV is in karst region on the limestone bed. This case is especially interesting. During analysis of the earthquake on Dec 10,2011 we perceived strange behavior of dissimilarity line of second referent day (red one in Figure 6). The spectrum of the second referent day was strongly dissimilar to all spectra

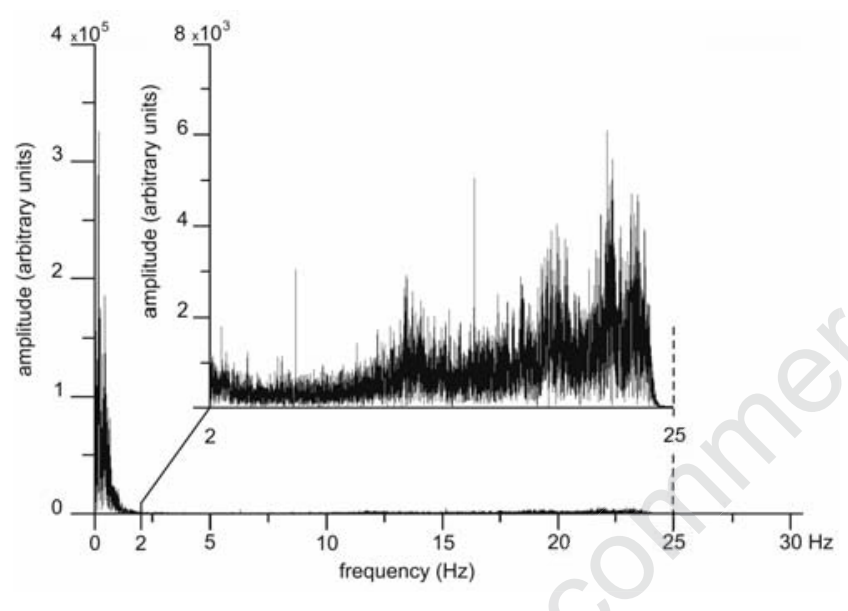

Figure 3. Complete spectrum and its high frequency (HF) part. Amplitude of HF component is for two orders of magnitude smaller than low frequency amplitude (example from Cačvina, Dec 10, 2011, 16:00 UTC).

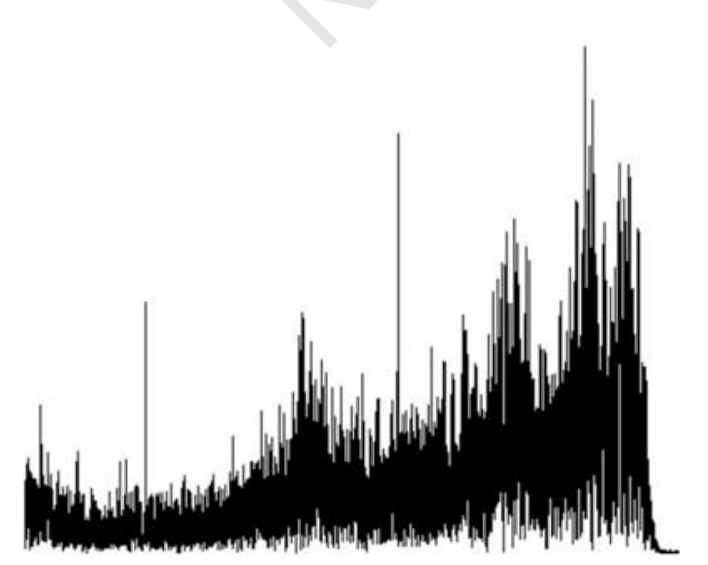

Figure 4. Example of the input image, same as part of Figure 3 but without repeated elements, i.e. axes and legends (Čačvina, Dec 10, 2011, 16:00 UTC).

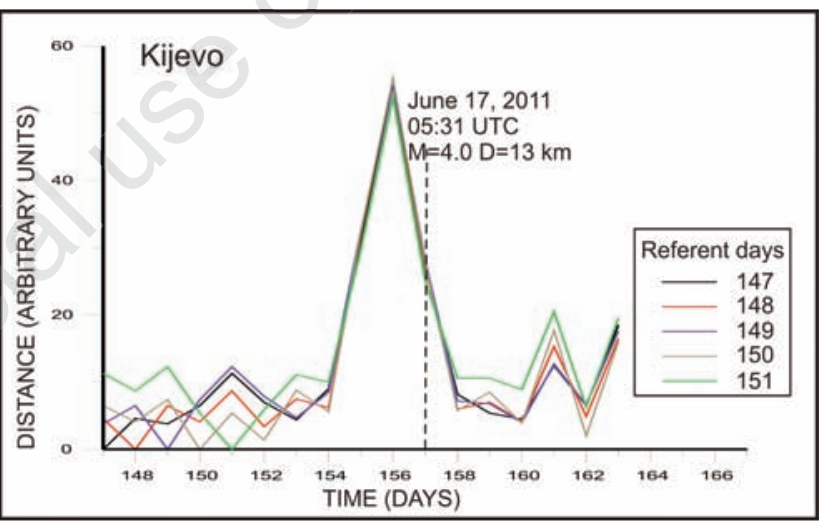

Figure 5. Euclidean distance in 6D space of affine invariants at Kijevo station from June $7\left(148^{\text {th }}\right.$ day of the year) to June 23 (166 ${ }^{\text {th }}$ day of the year), 2011. Colors indicate different referent day. Dashed vertical line denotes day of the earthquake. Sampling time: 04:00 UTC.

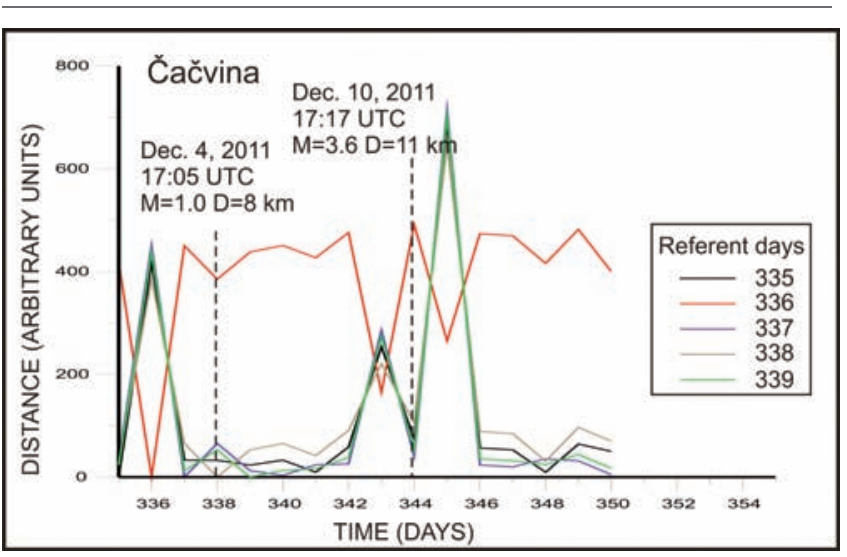

Figure 6. Euclidean distance in 6D space of affine invariants at Čačvina station from Dec $1\left(335^{\text {th }}\right.$ day of the year) to Dec 16 $\left(350^{\text {th }}\right.$ day of the year), 2011. Colors indicate different referent day. Dashed lines denote day of the earthquake. Sampling time: 16:00 UTC. 
except those before the earthquake and the day after. That means similar processes occurred on both days. Spectrum of second day is more similar to the spectrum of the day before than the spectrum of the day after the quake. Our hypothesis is that the preparation process is visible in HF spectrum before an earthquake, so we presumed that the process similar the preparation process had occurred on the second referent day. During more careful inspection of CACV seismograms, the earthquake which occurred on Dec 4, 2011, two days after second referent day, was found. It was small event $\left(\mathrm{M}_{\mathrm{L}} 1.0\right)$ with epicentral distance $\Delta=5 \mathrm{~km}$ from seismological station. It is possible that the magnitude is underestimated because the magnitude relation of CACV station is not very accurate for small distances. The most prominent maximum in Figure 6 is the one after $\mathrm{M}_{\mathrm{L}} 3.6$ earthquake. It corresponds to day with several aftershocks of this earthquake.

\section{Conclusions}

Microseismic noise recorded in particular time intervals before and after hypocentral time of the four earthquakes recorded at three seismological stations in Dinarides was examined. In all analized cases spectra of the noise showed increase of Euclidean distances between referent and other spectra one or two days before the earthquakes. Distances increased up to two orders of magnitude. Immediately after the earthquakes Euclidean distances dropped at the previous level.

Although all the predictions made by image moments approach were made a posteriori, the method could be useful for short term and near range a priori prediction. Application does not need expensive devices, just ordinary digital seismograph and computer. On the other hand, it needs dense network with seismographs every $20 \mathrm{~km}$. So, it could be suitable for compact defended areas such as highly populated cities.

Because the attenuation of elastic waves increase with frequency, epicentral distance could be the key parameter in using of HF noise as precursor. Small range of HF signals indicates that the preparation process has occurred near the station which means that the epicenter of the future earthquake will be in vicinity of the station. The number of close enough seismological stations with similar change of HF spectra could indicate size of the area affected with preparation process and perhaps serve as the measure of the cumulative energy of foreshocks, main shock and aftershocks in the source of future earthquake.

\section{References}

1. Lyubushin AA. Synchronization trends and rhythms of multifractal parameters of the field of low-frequency microseismic. Iz Phys Solid Earth 2009;45:381-94.

2. Lyubushin AA. Synchronization phenomena of low-frequency microseisms. ESC 32nd Gen. Assembly (Book of abstracts), Sept 6-10 2010, Montpelier, France, p 124, session ES6.

3. Lu C, Mai Y-W, Xie H. A sudden drop of fractal dimension: a likely precursor of catastrophic failure in disordered media. Philos Mag Lett 2005;85:33-40.

4. Levy EI. Possible prediction-modulation effect in the short-period sea-wave microseism. Tectonophysics 1992;202:203-7.

5. Sobolev GA, Lyubushin AA. Microseismic impulses as earthquake precursor. Iz Phys Solid Earth 2006;42:721-33.

6. Rao MVMS, Prasanna Lakshimi KJ, Nagaraja Rao GM, et al. Pre-failure damage caused by micro-cracks in rock: a laboratory study using acoustic emission. Proc Natl Seminar and Exibition on Nondestructive evaluation, 2009, pp. 323-327.

7. Korneev V. Acoustic emission precursor of M6.0 2004 Parkfied and M7.0 1989 Loma Prieta earthquakes. Scientific report, 2006; LBNL-60012. Berkeley: Lawrence Berkeley National Laboratory; 2006.

8. Crampin S, Evans R. Earthquake prediction: a new physical basis. Geophys J R Astr Soc 1984;76:147-56.

9. Ohnaka M. Earthquake source nucleation: a physical model for short - term precursors. Tectonophysics 1992;211:149-78.

10. Ellsworth WL, Hickman SH, Zobach MD, et al. Micro- nano- picoearthquakes at SAFOD: implications for earthquake rupture and fault mechanics. Eos Trans. AGU, 2007; 88: Fall Meet. Suppl., Abstract S12B05.

11. Bohnhoff M, Dresen G, Ellsworth WL, Ito H. Passive seismic monitoring of natural and induced earthquakes: case studies, future directions and socio-economic rele- vance. In: S. Cloetingh and J. Negendank, eds. New frontiers in integrated solid earth sciences. Dordrecht: Springer Science+Business Media B.V.; 2010.

12. Dieterich JH. Earthquake nucleation on faults with rate- and state- dependent strength. Tectonophysics 1992;211:115-34.

13. Boettcher MS, McGarr A, Johnson M. Extension of Gutenberg-Richter distribution to $\mathrm{Mw}-1.3$, no lower limit in sight. Geophys Res Lett 2009;36:L10307.

14. Kasahara J, Korneev V, Zhdanov MS. Active geophysical monitoring. Handbook of geophysical exploration:seismic exploration. Amsterdam: Elsevier; 2010.

15. Plenkers K, Schorlemmer D, Kwiatek G; JAGUARS Research Group. On the probability of detecting picoseismicity. Bull Seismol Soc Am 2011;101:2579-91.

16. Kwiatek G, Plenkers K, Dresen G; JAGUARS Research Group. Source parameters of picoseismic recorded at Mponeng deep gold mine, South Africa: implication for scaling relations. Bull Seismol Soc Am 2011;101:2592-608.

17. Gueguen Y, Palciauskas V. Introduction to the physics of rocks. Princeton, NJ: Princeton University Press; 1994.

18. Dasović I, Herak M, Herak D. Attenuation of coda waves in the contact zone between the Dinarides and Adriatic Microplate. Stud Geophys Geod 2012;56:231-47.

19. Kossobokov VG. Earthquake prediction: 20 years of global experiment. Nat Hazards 2012. [In press].

20. ORFEUS. Observatories and Research Facilities for European Seismology. Available from: http:/www.orfeus-eu.org/

21. McNamara D, Buland RP. Ambient noise levels in the continental United States. Bull Seismol Soc Am 1004;94:1517-27.

22. Bonefoy-Claudet S, Cotton F, Bard P-Y. The nature of noise wavefield and its applications for site effects studies. Earth-Sci Rev 2006;79:205-27.

23. Flusser J, Suk T. Pattern recognition by affine moment invariants. Pattern Recogn 1993;26:167-74.

24. Flusser J. Moment invariants in image analysis. Trans Eng Comput Technol 2006;11:196-201.

25. Reiss TH. Object recognition using algebraic and differential invariants. Signal Process 1993;32:367-95.

26. Zitová BJ, Flusser J. Landmark recognition using invariant features. Pattern Recogn Lett 1999;20:541-7. 